\title{
Development of Sodium Dodecyl Sulfate Based Electrochemical Sensor for Tartrazine Determination
}

\author{
C. Raril and J G. Manjunatha* \\ Dept of Chemistry, FMKMC College, Madikeri, \\ Mangalore University Constituent College, Karnataka, India
}

Received June 25, 2018; accepted August 5, 2020

\begin{abstract}
Sodium dodecyl sulfate modified carbon paste electrode (SDSMCPE) was prepared as a sensor for Tartrazine (TR) detection, at 0.2 M PBS, with pH 6.5. TR Electrocatalytic activity was found to be significantly improved compared to those obtained using a conventional paste electrode. TR electrochemical oxidation was investigated by cyclic voltammetry $(\mathrm{CV})$ and differential pulse voltammetry (DPV). SDSMCPE showed TR electrocatalytic oxidation in the linear range from $2 \times 10^{-5}$ to $5 \times 10^{-5} \mathrm{M}$ and from $6 \times 10^{-5}$ to $1.1 \times 10^{-4} \mathrm{M}$, with the detection limit of $52 \times 10^{-7} \mathrm{M}$. The proposed SDSMCPE-sensor exhibited enhanced electrochemical sensing, selectivity and stability for TRdetection. Finally, the use of a SDSMCPE-sensor was demonstrated for TRdetection in a lemon yellow powder sample.
\end{abstract}

Keywords: Tartrazine, electrochemical detection, carbon paste electrode and cyclic voltammetry.

\section{Introduction}

Tartrazine (TR) is a synthetic lemon yellow azo dye primarily used as a food coloring. Much food contains TR in various proportion, which depends upon the manufactures or persons preparing the food, and is harmful to human health [13]. TR appears to cause more allergic reactions in the human body than the other azo dyes. Serious side effects are causing potentially lethal asthma attacks, DNA damage and tumor, in the thyroid gland. Therefore, a selective and sensitive method for reliable TR determination would have a great interest. In recent years, there have been many methods that have been used to determine TR, such as spectrophotometry [4-5], high-performance liquid chromatography [6-7], electrophoresis [8] and electrochemical method [9-20].

Cyclic voltammetry $(\mathrm{CV})$ is the most versatile electroanalytical technique for the study of electroactive species and is widely used in the field of electrochemistry, organic chemistry, inorganic chemistry and biochemistry. Most of the chemists,

\footnotetext{
* Corresponding author. E-mail address: manju1853@gmail.com
} 
scientists and engineers have been using CV studies to evaluate the oxidation and reduction potential of functional groups and the side effects of other groups attached to them [21-26].

The application of surfactants modified electrodes for electrochemical detection of some biomolecules has been widely reported [27-32] and it has indicated that the presence of a small amount of surfactant on the electrode surface showed enhanced electrochemical activity for the detection of some biomolecules, as compared with a bare electrode.

In this study, we fabricated carbon paste electrode modified by sodium dodecyl sulfate (SDS) surfactant. TR was selected as an analytical molecule for electrochemical detection. Compared to bare carbon paste electrode (BCPE), sodium dodecyl sulfate modified carbon paste electrode (SDSMCPE) shows better sensitivity and selectivity for TR determination. The proposed mechanism for TR electrochemical oxidation is shown in Fig. 1 [33].

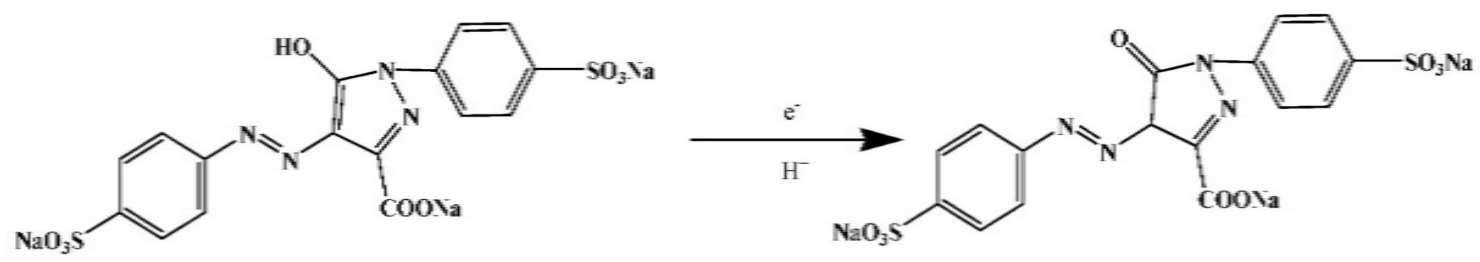

Figure 1. Scheme of TR oxidation mechanism.

\section{Experimental}

Chemicals and Reagents

SDS, TR, graphite and silicone oil were purchased from Nice Chemical Pvt. Ltd. Cochin. SDS stock solution $\left(25 \times 10^{-3} \mathrm{M}\right)$ was prepared by dissolving it in double distilled water. TR was of analytical grade and used without further purification. TR stock solution $\left(25 \times 10^{-4} \mathrm{M}\right)$ was prepared by dissolving it in distilled water. Phosphate buffer solution (PBS) was prepared by mixing $0.2 \mathrm{M}$ disodium phosphate and $0.2 \mathrm{M}$ monosodium phosphate. Distilled water was used throughout the preparation of solutions. Field Emission Scanning Electron Microscopy (FESEM) was obtained using the instrument operating at $5.00 \mathrm{kV}$ (DST-PURSE Laboratory, Mangalore University).

\section{Apparatus}

CV and DPV were obtained using an EA -201 electroanalyser (EA - 201 Chemilink system), a conjugation with a conventional three-electrode system and a personal computer for data storage and processing. A bare or MCPE were used as working electrode, saturated calomel electrode (SCE) as reference electrode and a platinum wire as auxiliary electrode. All the experiments were carried out at room temperature.

\section{Fabrication of BCPE and SDSMCPE}

The bare carbon paste electrode (BCPE) was prepared by mixing 70\% graphite powder and 30\% silicone oil in an agate mortar for about $15 \mathrm{~min}$, to get a 
homogeneous carbon paste. This carbon paste was then packed into the cavity of a Teflon tube (3 $\mathrm{mm}$ in diameter). Before placing the electrode for measurements, it was smoothed on a tissue paper, to get a smooth and uniform fresh surface. SDS modified carbon paste electrode was prepared by immobilizing $10 \mu \mathrm{L}$ of SDS on the electrode surface for $5 \mathrm{~min}$.

\section{Result and discussion}

\section{CPE and SDSMCPE surface morphologies}

FESEM technique was utilized to characterize the surface morphology of the fabricated electrode (Fig. 2). Fig. 2 (a) shows BCPE and SDSMCPE surface morphology (Fig. 2 (b)). BCPE surface appeared to be rough. However, SDS modified surface was smooth, with an uniform SDS deposition. This confirms that the carbon paste electrode was coated with SDS surfactant.

a)

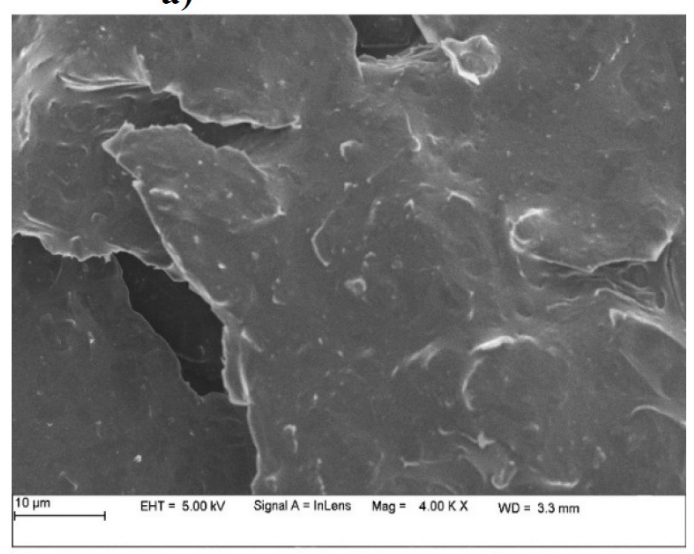

b)

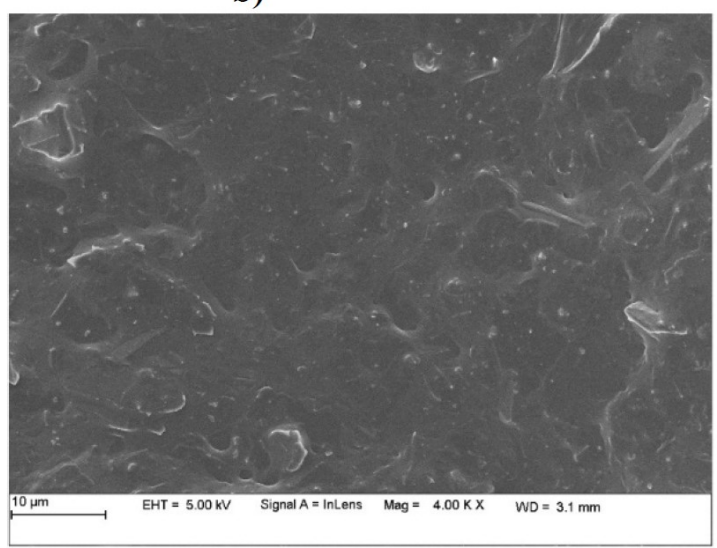

Figure 2. FESEM image of (a) BCPE (b) SDSMCPE.

\section{Optimization of experimental parameters}

Fig. 3 shows the effect of SDS concentration that was used in the range from 5 $\mu \mathrm{L}$ to $20 \mu \mathrm{L}$ (Fig. 3a), by immobilization on the carbon paste electrode, for investigating the variation of the oxidation peak current sensing for TR detection in $0.2 \mathrm{M}$ PBS, at $\mathrm{pH}$ 6.5. It was observed that the peak current maximum was obtained for $10 \mu \mathrm{L}$ of SDS immobilized carbon paste electrode. When it was used more than $10 \mu \mathrm{L}$ of SDS immobilization of carbon paste electrode, the peak current decreased. It clearly indicates that the critical micelle concentration (CMC) was reached at $10 \mu \mathrm{L}$. Hence, $10 \mu \mathrm{L}$ SDS immobilized carbon paste electrode was chosen as ideal for TR sensor studies. The dependence of the oxidation peak current of $3 \times 10^{-4} \mathrm{M}$ TR on different levels of SDS concentrations of immobilized carbon paste electrode is shown in Fig.3b.

\section{SDSMCPE Stability and Repeatability}

Repeatability was studied for 5 successive renewal of SDSMCPE of $3 \times 10^{-4} \mathrm{M}$ $\mathrm{TR}$ in a $0.2 \mathrm{M}$ PBS buffer solution ( $\mathrm{pH} \mathrm{6.5).} \mathrm{It} \mathrm{was} \mathrm{observed} \mathrm{that} \mathrm{the} \mathrm{relative}$ standard deviation (RSD, $\mathrm{n}=5$ ) was $4.35 \%$. SDSMCPE stability was evaluated 
by measuring SDS peak current after continuous scanning of 40 cycles in $0.2 \mathrm{M}$ PBS ( $\mathrm{pH}$ 6.5). The percentage of SDSMCPE degradation was calculated by using the following equation:

$$
\% \text { Degradation }=\frac{I_{p n}}{I_{p 1}} \quad[34]
$$

where $I_{p n}$ is the $n^{\text {th }}$ anodic peak current and $I_{p 1}$ is the first anodic peak current. The percentage of degradation was found to be $0.56 \%$, which shows that the modified electrode is stable.

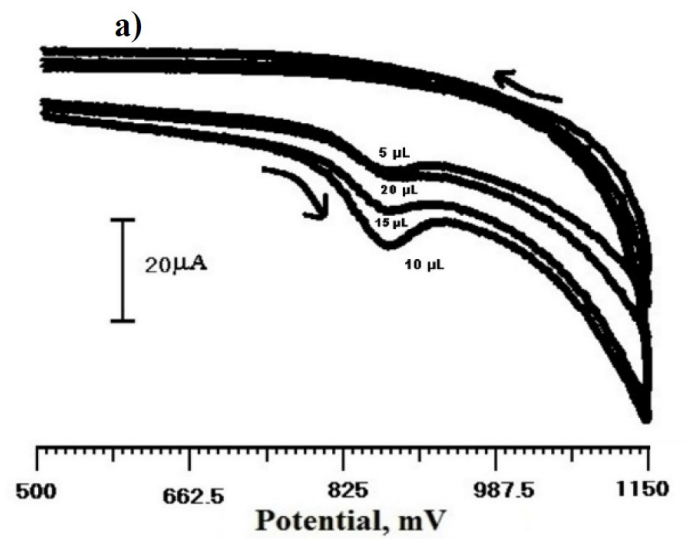

b)

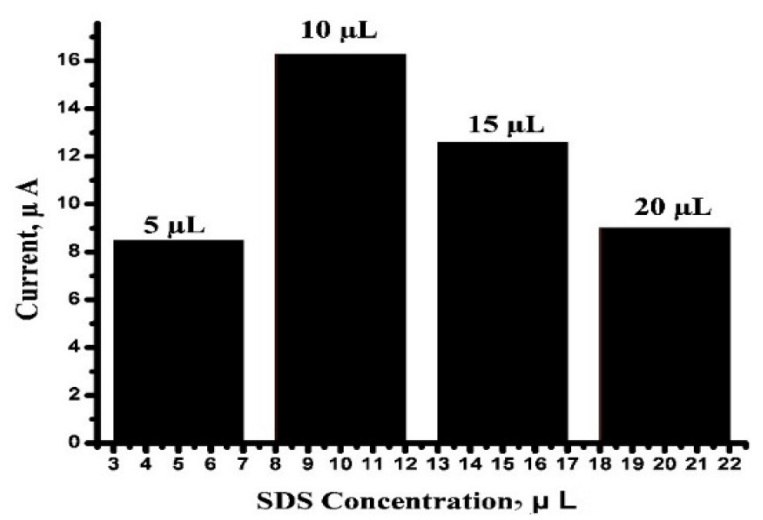

Figure 3. (a) Cyclic voltammogram of $3 \times 10^{-4} \mathrm{M}$ TR on a carbon paste electrode (CPE), at different SDS concentrations $(5 \mu \mathrm{L}, 10 \mu \mathrm{L}, 15 \mu \mathrm{L}$ and $20 \mu \mathrm{L})$, in $0.2 \mathrm{M}$ PBS $(6.5 \mathrm{pH})$, at the scan rate of $100 \mathrm{mV} / \mathrm{s}$. (b) Dependence of the oxidation peak current of $3 \times 10^{-4} \mathrm{M}$ TR on different levels of concentration.

\section{TR Electrochemical behavior}

Fig. 4 shows the cyclic voltammogram of the sensor, in TR presence and absence, in $0.2 \mathrm{M}$ PBS ( $\mathrm{pH} 6.5$ ), at a scan rate of $100 \mathrm{mV} / \mathrm{s}$, within the potential window from 500 to $1150 \mathrm{mV}$. There was no peak observed (solid line) in TR absence at SDSMCPE; only a background current was observed. When TR $\left(3 \times 10^{-4} \mathrm{M}\right)$ was added to the solution, a well-defined peak reached a potential of $873 \mathrm{mV}$, which indicates that the electrode response was proportional to the produced electroactive species. 


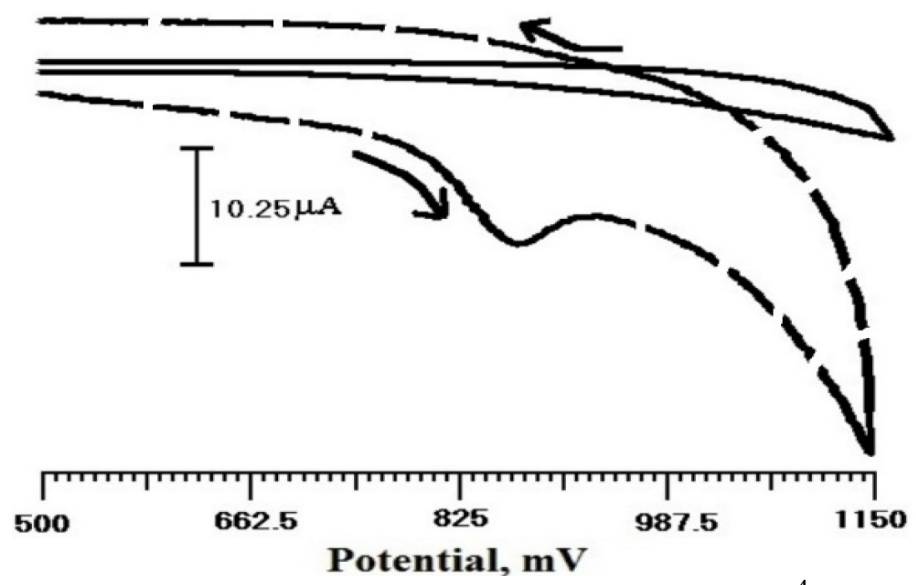

Figure 4. SDSMCPE cyclic voltammogram with TR $\left(3 \times 10^{-4} \mathrm{M}\right)$ (dashed line) and without TR (solid line), in 0.2 M PBS, at pH 6.5.

\section{TR Electrochemical response at SDSMCPE}

The cyclic voltammogram for TR in $0.2 \mathrm{M}$ PBS, with $\mathrm{pH} 6.5$, at a scan rate of $100 \mathrm{mV} / \mathrm{s}$ was investigated in the potential range from 500 to $1150 \mathrm{mV}$. Fig. 5 shows TR cyclic voltammogram at BCPE (solid line) and SDSMCPE (dashed line). At BCPE, a weak and broad oxidation peak was observed at about $906 \mathrm{mV}$. However, TR oxidation current on SDSMCPE was higher than that of BCPE, indicating the catalytic activity towards TR oxidation.

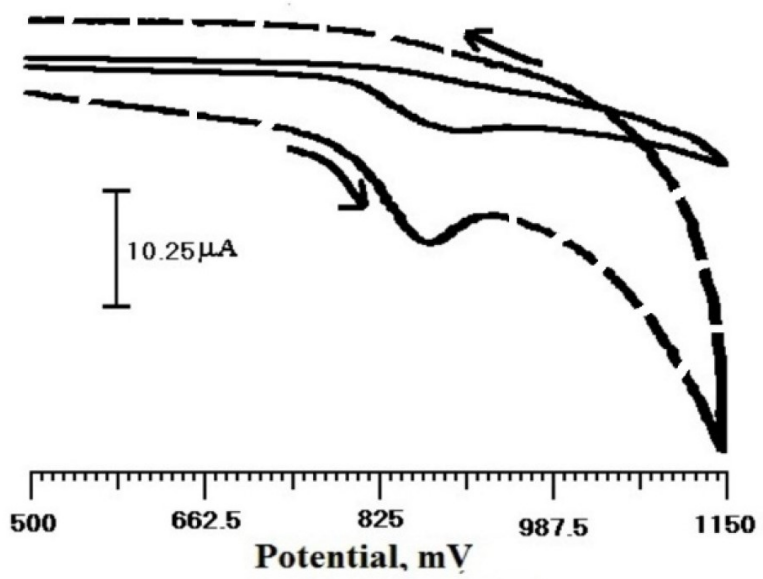

Figure 5. Cyclic voltammogram of TR $\left(3 \times 10^{-4} \mathrm{M}\right)$ in a $0.2 \mathrm{M}$ PBS buffer solution with pH 6.5, at BCPE (solid line) and SDSMCPE (dashed line).

Effect of scan rates on TR electrochemical response at SDSMCPE

TR cyclic voltammogram $\left(3 \times 10^{-4} \mathrm{M}\right)$ on SDSMCPE, at different potential scan

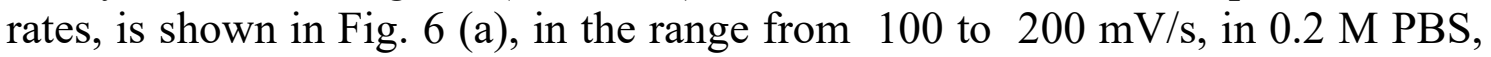
with $\mathrm{pH} 6.5$, as a supporting electrolyte.

With the increase in the scan rate, the oxidation peak current also increased gradually, indicating the direct electron transfer between TR and SDSMCPE surface. TR anodic peak current $\left(\mathrm{I}_{\mathrm{pa}}\right)$ was proportional to the square root of the scan rate $\left(v^{1 / 2}\right)$, with a linear regression equation: 


$$
I_{p a}(\mu A)=-21.00+3.65 v^{1 / 2}\left(m v^{-1}\right)^{\frac{1}{2}}
$$

with the correlation coefficient of 0.99203 (Fig. 6 b).

It indicates that TR oxidation is diffusion controlled. Peak potential, $\mathrm{E}_{\mathrm{pa}}$, and log (v) relation are explained in the following equation:

$$
E_{p a}=\frac{b}{2}(\log v)+k[35]
$$

where $v$ is the scan rate, $\mathrm{b}$ is the Tafel slope and also a constant value. From the $\mathrm{E}_{\mathrm{pa}}$ versus log $(v)$ graph (Fig. $6 \mathrm{c}$ ), the slope is 71.2. Therefore, the Tafel slope becomes 142.4. By considering $\alpha$ (transfer coefficient) as 0.43 , the number of electrons involved in TR oxidation reaction was calculated as $0.96 \sim=1$; the result was in accordance with the mechanism that has been explained in Fig. 1.

a)

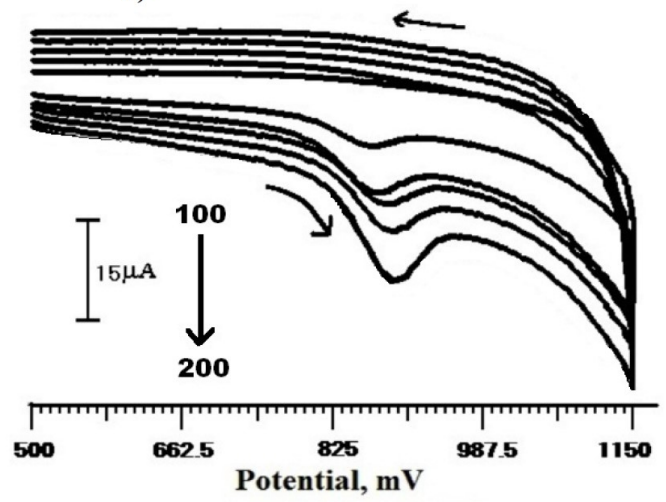

c) b)
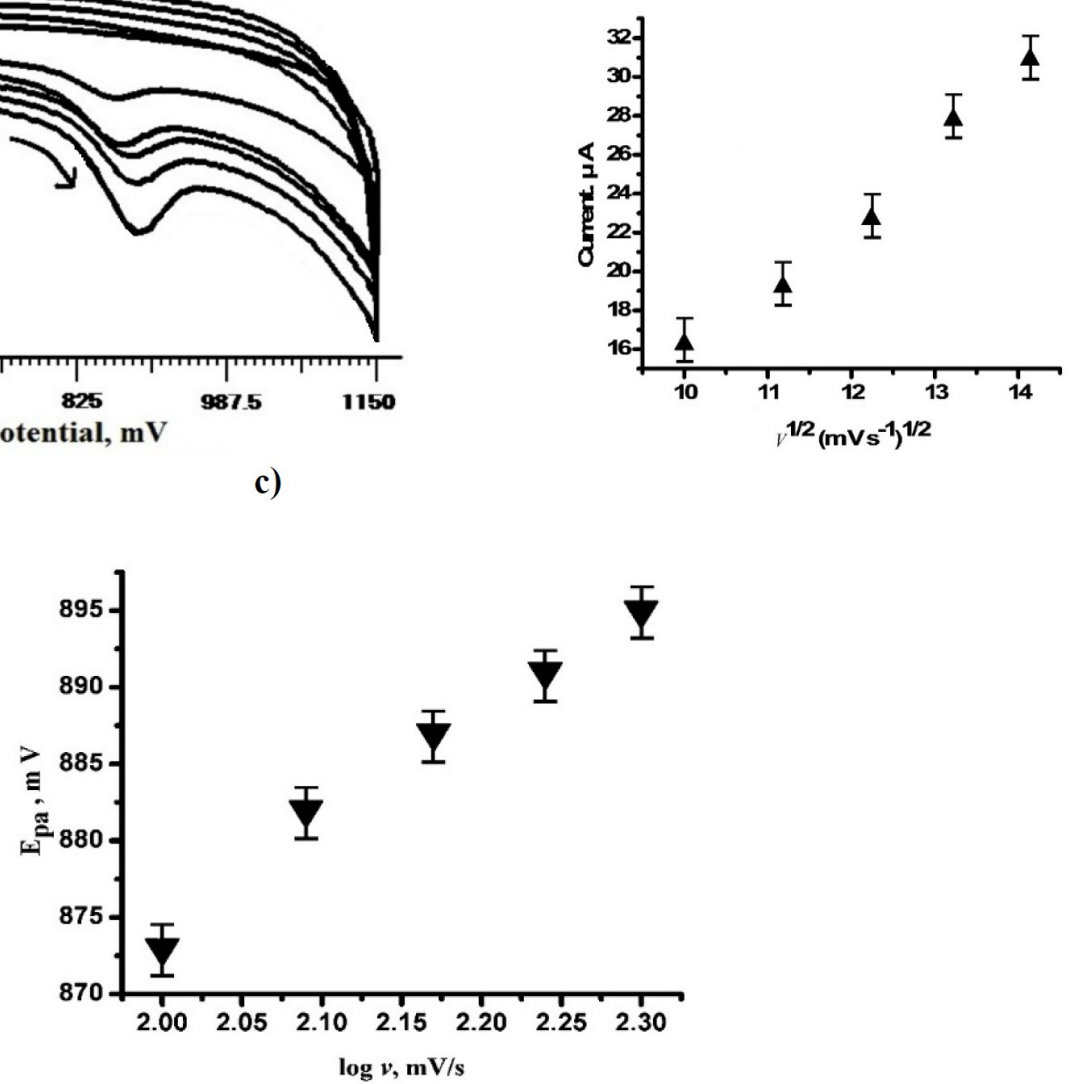

Figure 6. (a) TR cyclic voltammogram $\left(3 \times 10^{-4} \mathrm{M}\right)$ at SDSMCPE, with $\mathrm{pH} 6.5$, at various scan rates, from 100, 125, 150, 175 to $200 \mathrm{mV} / \mathrm{s}$; (b) anodic peak current ( $\mathrm{I}_{\mathrm{pa}}$ ) Vs square root of scan rate $\left(v^{1 / 2}\right) ;$ (c) $\mathrm{E}_{\mathrm{pa}} \mathrm{Vs} \log (v)$.

\section{Effect of pH on peak potential and peak current}

Fig. 7 (a) shows the effect of $\mathrm{pH}$ on SDSMCPE electrochemical response in $3 \times 10^{-4} \mathrm{M}$ TR, with the $\mathrm{pH}$ range from 6.0 to 8.0 , in a $0.2 \mathrm{M}$ PBS solution. As the $\mathrm{pH}$ increased from 6.0 to 8.0, the anodic peak potential shifted towards a negative value, and a well-defined peak obtained with high peak current, at $\mathrm{pH}$ 
6.5, are shown in Fig. 7 (b). Thus, the solution of $\mathrm{pH} 6.5$ was used for TR determination. TR anodic peak potential shifted from $911 \mathrm{mV}$ to $830 \mathrm{mV}$, with respect to the $\mathrm{pH}$ from 6.0 to 8.0 . The potential diagram was constructed by plotting anodic peak potential, $\mathrm{E}_{\mathrm{pa}}, \mathrm{Vs} \mathrm{pH}$ (Fig. 7 (c)). The linear regression equation is given below:

$$
E_{p a}=1135.2-38.6 p H
$$

with a correlation coefficient $(\mathrm{R})=0.97109$.

a)

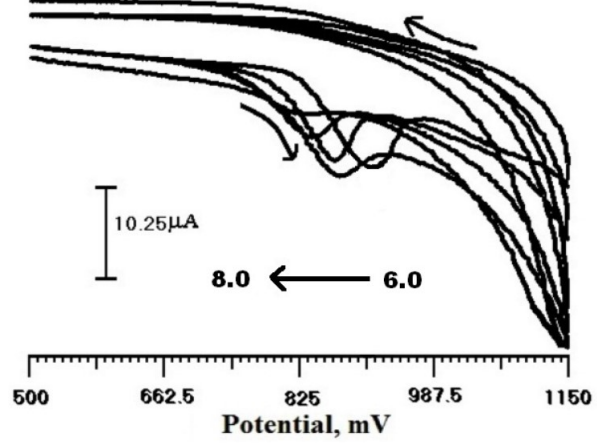

c) b)

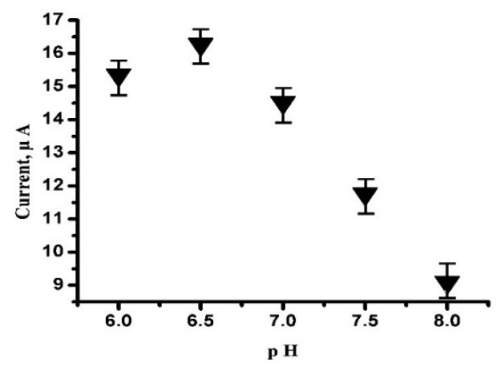

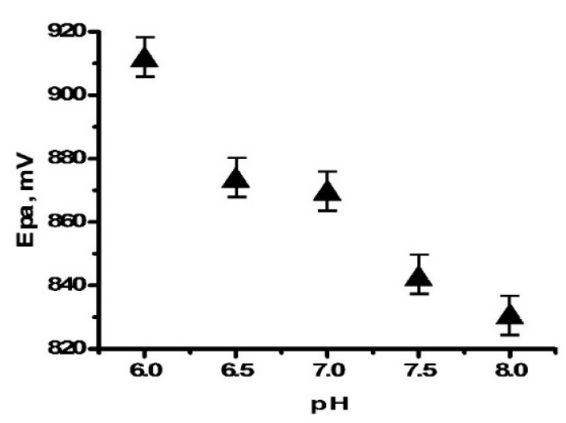

Figure 7. (a) Cyclic voltammogram at SDSMCPE in $0.2 \mathrm{M}$ PBS, with different $\mathrm{pH}$ values $(6.0,6.5,7.0,7.5$ and 8.0$)$, containing TR $\left(3 \times 10^{-4} \mathrm{M}\right)$; (b) anodic peak current ( $\left.\mathrm{I}_{\mathrm{pa}}\right) \mathrm{Vs} \mathrm{pH}$ for TR; (c) plot of anodic peak potential ( $\left.\mathrm{E}_{\mathrm{pa}}\right) \mathrm{Vs} \mathrm{pH}$, at SDSMCPE.

\section{TR calibration plot and limit of detection}

$\mathrm{CV}$ is a sensitive electrochemical technique which is used to determine TR linear range and detection limit. The calibration plot for TR determination at SDSMCPE, with pH 6.5 PBS, at the scan rate of $100 \mathrm{mV} / \mathrm{s}$, is shown Fig. 8. TR anodic peak current response is directly proportional to TR concentration, over a range from $2 \times 10^{-5}$ to $5 \times 10^{-5} \mathrm{M}$ and $6 \times 10^{-5}$ to $1.1 \times 10^{-4} \mathrm{M}$. The linear regression equation (4) is,

$$
I_{p a}(\mu A)=6.182 \times 10^{-8}+0.048 C(M)
$$

with a correlation coefficient of 0.99731 .

The detection limit $\left(\mathrm{DL}=3 \mathrm{~S}_{\mathrm{b}} / \mathrm{m}\right.$, where $\mathrm{S}_{\mathrm{b}}$ is the standard deviation of the blank response and $\mathrm{m}$ is the slope of the calibration plot) [36-37] and limit of quantification $\left(10 \mathrm{~S}_{\mathrm{b}} / \mathrm{m}\right)$ were found at the values of $52 \times 10^{-7} \mathrm{M}$ and $17 \times 10^{-6} \mathrm{M}$, 
respectively. The limit of detection and limit of quantification were used to describe the smallest concentration of an analyte that can be reliably measured by an analytical procedure. The performance of the developed electrode is compared and listed in Table 1, in reference to the already published research articles [9, $10,11,12]$. The fabricated electrode shows a good sensitivity $(0.048 \mu \mathrm{A} / \mu \mathrm{M})$ and good stability towards TR determination.

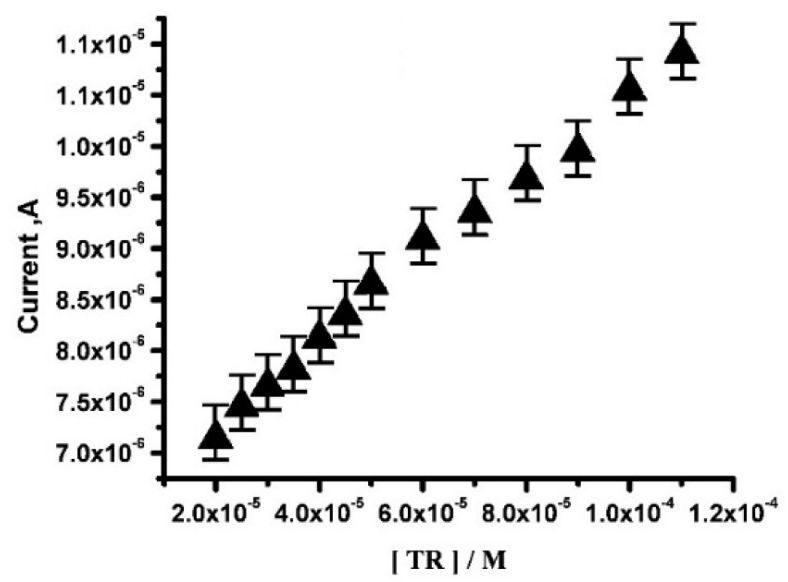

Figure 8. Calibration plot for TR determination at SDSMCPE, with PBS at $\mathrm{pH} 6.5$, at the scan rate of $100 \mathrm{mV} / \mathrm{s}$.

Table 1. Detection limit comparison of SDSMCPE with some other modified electrodes for TR determination.

\begin{tabular}{|c|c|c|}
\hline Electrode & Detection limit (M) & Reference \\
\hline Alumina microfibers/CPE & $2 \times 10^{-9}$ & 9 \\
\hline Carbon nanotubes/GCE & $188 \times 10^{-9}$ & 10 \\
\hline Acetylene black/GCE & $187 \times 10^{-9}$ & 11 \\
\hline Gold nanoparticle/CPE & $2 \times 10^{-9}$ & 12 \\
\hline SDSMCPE & $52 \times 10^{-7}$ & This work \\
\hline
\end{tabular}

TR electrocatalytic oxidation by DPV, at BCPE and SDSMCPE

Fig. 9 depicts TR DPV response $\left(3 \times 10^{-4} \mathrm{M}\right)$, at BCPE and SDSMCPE, in $0.2 \mathrm{M}$ PBS ( $\mathrm{pH} 6.5$ ), in the potential range from 500 to $1150 \mathrm{mV}$. The anodic peak potential for TR oxidation at SDSMCPE was found to be $867 \mathrm{mV}$. The oxidation current obtained for SDSMCPE was higher than that obtained for TR at BCPE. Hence, it could be concluded that SDSMCPE improves the characteristics of TR oxidation.

\section{Analytical application}

In order to illustrate the application of the suggested sensor in real sample analysis, tiger lemon yellow powder was selected, having been purchased from a local supermarket. The content was determined using standard addition method. The value of the recovery was in the range from 97.1 to $104 \%$, which indicated that the fabricated sensor represented a good and easy way of monitoring TR in real samples. 


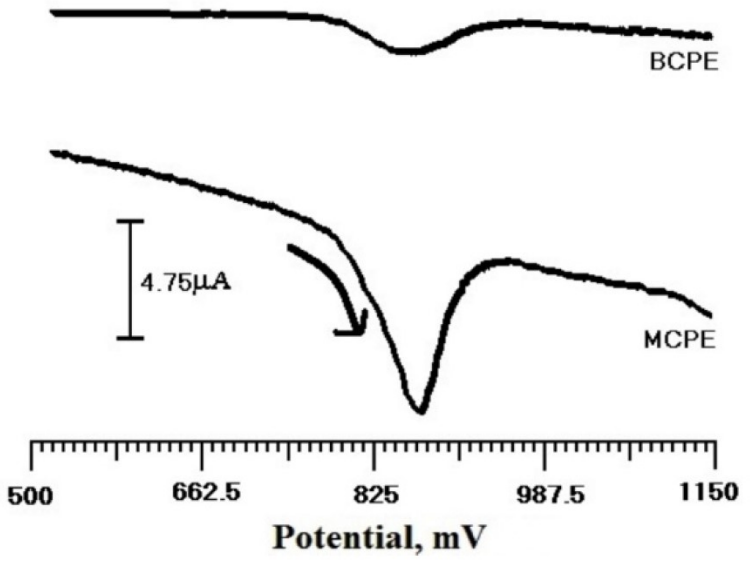

Figure 9. DPV of a solution containing TR $\left(3 \times 10^{-4} \mathrm{M}\right)$, in $0.2 \mathrm{M}$ PBS, at BCPE and SDSMCPE.

\section{Conclusion}

This work demonstrates that the modified CPE was fabricated by using SDS through immobilization technique. TR voltammetric behavior was investigated by $\mathrm{CV}$ in $0.2 \mathrm{M}$ PBS ( $\mathrm{pH}$ 6.5). The influence of different parameters on TR oxidation, such as $\mathrm{pH}$, scan rate and concentration was also investigated. TR oxidation was found to be irreversible with a controlled diffusion process. SDSMCPE exhibited excellent electrocatalytic activity and well voltammetric performance during TR oxidation. The sensor was characterized by a good sensitivity, selectivity and fast response and low detection limit $\left(52 \times 10^{-7} \mathrm{M}\right)$, with satisfactory stability, repeatability and good potential application towards the TR determination in a real sample.

\section{Novelty statement}

In this work, it was created a novel electroanalytical method which showed good sensitivity, and which is comparable with previous reports. The method is based on the subduing of the peak current of the modifier, due to the analyte in a modified carbon paste electrode.

\section{Acknowledgments}

We gratefully acknowledge the financial support (KFIST) from the VGST, Bangalore, under Research Project No. KSTePS/VGST-KFIST(L1)20162017/GRD-559/2017-18/126/333, 21/11/2017, and from Mangalore University under the Research Project order No. MU/DEV/2014-15/D3 D.t:30.04.2016.

\section{References}

1. Lopez de Alba PL, Lopez Martinez L, Cerda V, et al. Simultaneous determination of tartrazine, sunset yellow and allure red in commercial soft drinks by multivariate spectral analysis. Quim Anal. 2001;20:63-72. 
2. Rowe KS, Rowe KJ. Synthetic food coloring, and behavior: a dose-response effect in a double-blind, placebo-controlled, repeated-measures study. J Pediatr. 1994;125:691-698.

3. Stevenson DD, Simon RA, Lumry WR, et al. Adverse reactions to tartrazine. J Allergy Clin Immunol. 1986;78:182-191

4. Erdal D, Emine B, Murat K, et al. Spectrophotometric multicomponent determination of sunset yellow, tartrazine and allure red in soft drink powder by double divisor-ratio spectra derivative, inverse least-squares and principal component regression methods. Talanta. 2002;58:579-594.

5. Berzas Nevado JJ, Rodriguez Flores J, et al. Simultaneous determination of tartrazine and sunset yellow by derivative spectrophotometry and ratio spectra derivative. Talanta. 1993;40:1391-1396.

6. Maria JC, Agustina VS, Natalia EL, et al. Fast-chromatographic method for the determination of dyes in beverages by using high- performance liquid chromatography-diode array detection data and second-order algorithms. J Chromatogr A. 2009;1216:7063-7070.

7. Yoshioka N, Ichihashi K. Determination of 40 synthetic food colors in drinks and candies by high-performance liquid chromatography using a short column with photodiode array detection. Talanta. 2008;74:1408-1413.

8. Kyung-Sun L, Muhammad JAS, So-Hee P, et al. Electrophoretic analysis of food dyes using a miniaturized microfluidic system. Electrophoresis. 2008;29:1910-1917.

9. Yuanyuan Z, Lintong H, Xin L, et al. Highly-sensitive and rapid detection of ponceau $4 \mathrm{R}$ and tartrazine in drinks using alumina microfibers-based electrochemical sensor. Foodchem. 2015;166:352-357.

10. Weikang Z, Tao L, Xiaojiang Z, et al. Surface-enhanced oxidation and detection of Sunset Yellow and Tartrazine using multi-walled carbon nanotubes film-modified electrode. Colloids Surf B: Biointerfaces. 2009;74:28-31.

11. Xiaofeng Y, Haibin Q, Miaomiao G, et al. Simultaneous detection of Ponceau 4R and tartrazine in food using adsorptive stripping voltammetry on an acetylene black nanoparticle-modified electrode. J Sci Food Agric. 2001;91:2821-2825.

12. Ghoreishi SM, Behpour M, Golestaneh M. Simultaneous determination of Sunset Yellow and Tartrazine in soft drinks using gold nanoparticles carbon paste electrode. Food Chem. 2012;132:637-641.

13. Gan T, Sun J, Meng W, et al. Electrochemical sensor based on graphene and mesoporous $\mathrm{TiO} 2$ for the simultaneous determination of trace colourants in food. Food Chem. 2013;141:3731-3737.

14. Tian G, Junyong S, Shuqin C, et al. One-step electrochemical approach for the preparation of graphene wrapped-phosphotungstic acid hybrid and its application for simultaneous determination of sunset yellow and tartrazine. Electrochim Acta. 2012;74:151-157.

15. Xiaoliang Y, Yongling D, Daban L, et al. Fabrication of $\beta$-cyclodextrincoated poly (diallyldimethylammonium chloride)-functionalized graphene composite film modified glassy carbon-rotating disk electrode and its 
application for simultaneous electrochemical determination colorants of sunset yellow and tartrazine, Anal Chim Acta. 2013;779:22-34.

16. Tian G, Junyong S, Qiong W, et al. Graphene Decorated with Nickel Nanoparticles as a Sensitive Substrate for Simultaneous Determination of Sunset Yellow and Tartrazine in Food Samples. Electroanalysis. 2013;25:1505-1512.

17. Majidi, MR, Fadakar Bajeh BR, Naseri. Carbon Nanotube-Ionic Liquid (CNT-IL) Nanocomposite Modified Sol-Gel Derived Carbon-Ceramic Electrode for Simultaneous Determination of Sunset Yellow and Tartrazine in Food Samples. Food Anal Method. 2012;6:1388-1397.

18. Roberta AM, Bruna CL, Romeu CRF, et al. Simultaneous voltammetric determination of synthetic colorants in food using a cathodically pretreated boron-doped diamond electrode. Talanta. 2012;97:291-297.

19. Lijuan Z, Baizhao Z, Faqiong Z. Electrochemical determination of tartrazine using a molecularly imprinted polymer-multiwalled carbon nanotubes - ionic liquid supported $\mathrm{Pt}$ nanoparticles composite film coated electrode. Electrochim Acta. 2014;146:611-617.

20. Shuhai J, Jinfeng $X$, Peidong $X$, et al. A Novel Molecularly Imprinted Sensor for Direct Tartrazine Detection. Anal Lett. 2014;47:323-330.

21. Nagaraj PS, Deepti SN, Girish TK, et al. Electrochemical behavior of thiosalicylic acid at $\gamma$-Fe2O3 nanoparticles and clay composite carbon electrode. Electrochim Acta. 2018;269:204-211.

22. Shikandar DB, Nagaraj PS, Raviraj MK. Construction of nanoparticles composite sensor for atorvastatin and its determination in pharmaceutical and urine samples. Sensors Actuat B. Chem. 2018;255:1462-1470.

23. Sathish Reddy, Kumara Swamy BE, Seeram R, et al. NiO Nanoparticles Based Carbon Paste as a Sensor for Detection of Dopamine. Int $\mathrm{J}$ Electrochem Sci. 2018;13:5748-5761.

24. Deepti SN, Nagaraj PS. Voltammetric Response and Determination of an Anti-Inflammatory Drug at a Cationic Surfactant-Modified Glassy Carbon Electrode. J Surfactants Deterg. 2016;19:1071-1079.

25. Sathish Reddy, Kumara Swamy BE, Jayadevappa H. CuO nanoparticle sensor for the electrochemical determination of dopamine. Electrochim Acta. 2012;61:78-86.

26. Shikandar DB, Nagaraj PS, Kulkarni RM, et al. Silver-Doped Titania Modified Carbon Electrode for Electrochemical Studies of Furantril. ECS J Solid State Sci Technol. 2018;7:Q3215-Q3220.

27. Manjunatha JG, Kumara Swamy BE, Gilbert O, et al. Sensitive Voltammetric Determination of Dopamine at Salicylic Acid and TX-100, SDS, CTAB Modified Carbon Paste Electrode. Int J Electrochem Sci. 2010;5:682-695.

28. Manjunatha JG, Kumara Swamy BE, Deepa R, et al. Electrochemical studies of Dopamine at Eperisone and Cetyl Trimethyl Ammonium Bromide Surfactant modified Carbon paste electrode: A Cyclic Voltammetric Study. Int J Electrochem Sci. 2009;4:662-671. 
29. Manjunatha JG, Deraman M. Graphene Paste Electrode Modified with Sodium Dodecyl Sulfate Surfactant for the Determination of Dopamine, Ascorbic Acid and Uric Acid. Anal Bioanal Electrochem. 2017;9:198-213.

30. Manjunatha JG, Kumara Swamy BE, Mamatha GP, et al. Electrocatalytic Response of Dopamine at Mannitol and Triton X-100 Modified Carbon Paste Electrode: A Cyclic Voltammetric Study. Int J Electrochem Sci. 2009;4:1706-1718.

31. Manjunatha JG. Surfactant modified carbon nanotube paste electrode for the sensitive determination of mitoxantrone anticancer drug. Int $\mathrm{J}$ Electrochem Sci. Eng.2017;7:39-49

32. Zheng J, Zhou X. Sodium dodecyl sulfate-modified carbon paste electrodes for selective determination of dopamine in the presence of ascorbic acid. Bioelectrochem. 2007;70:408-415.

33. Kobun R, Siddiquee S, Shaarani S. Md, a Review of Extraction and Analytical Methods for the Determination of Tartrazine (E 102) in Foodstuffs. Crit Rev Anal Chem. 2016;3:309-324.

34. Manjunatha JG, Deraman M, Basri NH, et al. Sodium dodecyl sulfate modified carbon nanotubes paste electrode as a novel sensor for the simultaneous determination of dopamine, ascorbic acid, and uric acid. C R Chimie. 2014;17:465-476.

35. Karim-Nezhad G, Khorablou Z, Zamani M, et al. Voltammetric sensor for tartrazine determination in soft drinks using poly (p-aminobenzenesulfonic acid)/zinc oxide nanoparticles in carbon paste electrode. J Food Drug Anal. 2017;25:293-301.

36. Manjunatha JG. Electroanalysis of estriol hormone using electrochemical sensor. Sens Bio-Sensin Res. 2017;16:79-84.

37. Manjunatha JG, A novel poly (glycine) biosensor towards the detection of indigo carmine: A voltammetric study. J Food Drug Anal. 2018;26(1):292299. 